\title{
DOCÊNCIA E GÊNERO: O PROFESSOR HOMEM NA EDUCAÇÃO INFANTIL
}

\author{
PATRÍCIA GOUVÊA NUNES \\ Instituto Federal de Educação, Ciência e Tecnologia Goiano, Rio Verde, \\ Goiás, Brasil \\ LÚCIA RINCON HELENA AFONSO \\ Pontifícia Universidade Católica de Goiás (PUCGO), Goiânia, Goiás, \\ Brasil
}

\begin{abstract}
Resumo: Neste artigo, apresentamos resultados obtidos em pesquisa que objetivou investigar e analisar o professor homem na Educação Infantil da Rede Municipal de Ensino de Rio Verde (GO) e como este é percebido pela comunidade escolar. O estudo desenvolveu-se mediante questionamentos sobre a docência do professor homem na Educação Infantil e ao habitus do reconhecimento de mulheres nessa etapa. A atuação docente dos professores homens do município de Rio Verde nessa etapa é marcada por relações de poder que permeiam as relações sociais e de gênero presentes nos espaços sociais, e que homens em espaços considerados historicamente como femininos apresentam características da prática docente associadas à masculinidade tradicional, como um habitus cultural mantido pela violência simbólica.
\end{abstract}

Palavras-chave: Docência. Relações Sociais e de Gênero. Educação Infantil. Habitus.

\section{MASCULINO E FEMININO: GÊNEROS CONSTRUÍDOS SOCIALMENTE}

Considerando o gênero como constitutivo das relações sociais entre homens e mulheres, para compreender essas relações, em qualquer configuração social ou profissional, é preciso recorrer às suas bases de sustentação, que se encontram na divisão sexual do trabalho. Assim é possível compreender como essas bases perpassam a profissão docente e constituem os/as profissionais que nela atuam. Assim, esta discussão se impôs quando o objetivo da dissertação a ser desenvolvida centralizou-se em investigar sobre a presença de homens professores na Educação Infantil.

A divisão social do trabalho, processo pelo qual as atividades de produção e reprodução social são diferenciadas, especializadas e desempenhadas por diferentes pessoas, pode ocorrer através da separação das atividades de produção de bens e serviços, de acordo com o sexo das pessoas que as realizam, caracterizando a divisão sexual do trabalho. 
Na nova definição de trabalho, possibilitada pela teorização da divisão sexual do trabalho, o trabalho doméstico, o não remunerado e o informal também são considerados como trabalho assalariado. Para desenvolvimento das atividades de trabalho requer-se atributos que são associados à mulher e ao homem. Desse modo, trabalho profissional assalariado, trabalho doméstico, produção e reprodução, salário e família, classe social e sexo social são consideradas categorias indissociáveis (HIRATA, 2002, p. 232 apud Rocha, 2012, p. 50)

A emergência do conceito de gênero na busca para explicar as relações entre homens e mulheres permitiu perceber que os papéis masculinos e femininos são construções sociais nas quais relações de poder e hierarquias estão presentes. A divisão sexual do trabalho deixa de ser vista como um processo natural, mas como uma expressão da assimetria das relações entre homens e mulheres.

Nos estudos de Scott (1994), a autora expõe que foi por volta do final do século XIX que se estabeleceu de forma mais forte a associação das mulheres com mão-de-obra desvalorizada, ainda que, frequentemente, ao longo da história da sociedade de classes, às mulheres eram reservados espaços específicos caracterizados por uma inferioridade hierárquica, por atividades adaptadas a suas capacidades consideradas "inatas". As atividades que requeriam delicadeza, paciência e perseverança eram oferecidas às mulheres, enquanto atividades que precisavam de força muscular e velocidade eram designadas aos homens.

Tal discussão remete ao entendimento das atividades de trabalho distribuídas numa sociedade patriarcal entendida como, segundo Scott (1994), uma forma de organizar socialmente relações, onde as mulheres estão, de maneira hierárquica, subordinadas aos homens, gerando uma supremacia masculina ditada pelos valores do patriarcado, perante as atividades femininas.

Portanto, o patriarcalismo perpassa a divisão sexual do trabalho, favorecendo a destinação das mulheres a trabalhos com ocupações precárias. $O$ emprego precarizado, todavia, não se restringiu às mulheres, possibilitando a conjectura de que seu trabalho representa um teste de viabilidade desse modelo para toda a classe trabalhadora, uma vez que "as mulheres foram pioneiras ao ocupar postos de trabalhos precários, que estavam por vir para ambos os sexos, no contexto da reestruturação produtiva" (NOGUEIRA, 2004, p. 13).

As atividades de trabalho têm apresentado um elemento praticamente constante: a permanência das desigualdades de gênero no que se refere aos rendimentos salariais. Bruschini (2007) relata que, seja qual for a ocupação, as mulheres recebem menores salários do que os homens, sendo que seus rendimentos são aproximadamente $64 \%$ dos salários masculinos. Assim, a feminização de uma atividade profissional pode vir acompanhada por um processo de rebaixamento salarial e de desvalorização da atividade. Se o gênero é o elemento fundamental para que essa situação se configure, é preciso compreender como se constitui essa categoria de análise.

Mediante o que é proposto neste estudo, é fundamental articular a divisão sexual do trabalho, as relações sociais e de gênero à profissão docente como atividade de trabalho desenvolvida majoritariamente por mulheres. Para tanto, inicia-se com um recorte histórico sobre os estudos feministas como "as diferenças que se constatavam nos 
comportamentos de homens e mulheres não eram dependentes do 'sexo' como questão biológica, mas sim eram definidos pelo 'gênero' e, portanto, ligadas à cultura" (PEDRO, 2005, p.78).

Scott $(1995$, p. 13) afirma que "Gênero é a organização social da diferença sexual percebida (...)", ressaltando que não significa que gênero reflita as diferenças físicas e naturais entre homens e mulheres, mas que gênero é o saber que estabelece sentidos para as diferenças corporais. Esses sentidos podem variar de acordo com as culturas, os grupos sociais e no tempo, já que somente o corpo não determina a divisão social que será estabelecida.

Em suma, aqui se entende gênero como "um elemento constitutivo de relações sociais baseadas nas diferenças percebidas entre os sexos e [...] uma forma primária de dar significado às relações de poder" (SCOTT, 1995, p. 86). Trabalha-se, então, com o entendimento de Scott (1995) de que gênero e poder, portanto, são construções recíprocas, sendo as mudanças e crises sociais que surgem de contextos desiguais como parte da dinâmica da transformação política e social em diferentes tempos e lugares, o que permite afirmar que homens e mulheres entendidos como masculino e feminino são articulados a relações de poder.

Dessa forma, as relações de poder entre homens e mulheres vão se constituindo como fatores que favorecem sua distinção "numa base a partir da qual se poderia identificar o lugar do homem e da mulher nos aspectos psicológicos, culturais, sociais e econômicos da vida humana, de forma transcultural" (CARVALHO, 1999, p. 26).

Tais colocações contribuem, segundo Louro $(2011$, p. 25), para que se reflita sobre as funções sociais do homem e da mulher, dando visibilidade à necessidade de se “demonstrar que não propriamente as características sexuais, mas é a forma como essas características são representadas ou valorizadas, efetivamente, o que é feminino ou masculino em uma dada sociedade e em um dado momento histórico".

Ampliando os sentidos e a argumentação de Louro (2011), pensar em gênero é pensar na possibilidade de se entender como as relações de gênero se consolidam na sociedade e como estabelecem a divisão sexual dos espaços sociais, que homens e mulheres ocupam. Já a sociedade incorporou essa divisão desde "quando a urbanização e a industrialização provocaram mudanças profundas nas formas de organização da vida social [...]" (CARVALHO, 1999, p. 27).

Ressalta-se que a divisão social e sexual do trabalho é colocada aqui para se compreender como a profissão docente foi sendo historicamente atribuída às mulheres como extensão das atividades de trabalho designado socialmente a elas, confinadas à esfera "da reprodução doméstica e vida pessoal" e excluídas "da produção social do Estado", a esfera dominante, identificada com os homens (CHODOROW, 1990, p. 25, apud CARVALHO, 1999, p. 26).

Falar em divisão das funções sociais entre homens e mulheres, como já se disse, significa remeter à reflexão sobre a "masculinidade hegemônica" colocada por Connell (1995, p.192), a qual pretende explicar como se tornam legítimas no âmbito social, sendo esta "a configuração de práticas de gênero que incorpora a resposta comumente aceita ao problema da legitimação do patriarcado, que garante (ou é tomada como garantia) a posição dominante dos homens e da subordinação das mulheres".

"As masculinidades estão constantemente mudando na história" (CONNELL, 1995, p. 191). O modo de ser homem, "macho", depende do contexto histórico e cultural 
no qual se vive, significando dizer que para cada sociedade existem modelos de masculinidades, também passíveis de modificações, e que o modo como os homens vivem os espaços ditos femininos ou masculinos está referenciado ao contexto social em que vivem. Connell (1995) apresenta o conceito de "masculinidades" como a disposição dos homens na estrutura social das relações de gênero e por meio dessa conceituação o autor afirma que não se pode falar em somente uma, mas em diversas masculinidades social-historicamente construídas, sendo uma delas a portadora de um status de "hegemônica" e as demais masculinidades periféricas as concorrentes ou afirmadoras dessa.

Para discutir a presença de homens na Educação Infantil, é importante "sempre lembrar das relações de poder que estão aí envolvidas" (CONNELL, 1995, p. 188) e que se constroem como prática social, ora conservando tradições que ordenam tarefas masculinas e femininas, ora criando modalidades da divisão sexual de tarefas entre essas.

Compreende-se que as relações de gênero são construídas historicamente, reforçando as relações de poder, sendo considerado o que já está estabelecido socialmente, e também como homens e mulheres vivenciam, interiorizam suas experiências e dão significado a elas. Da mesma forma, é necessário considerar a produção das subjetividades a partir das ações da humanidade devidamente historicizadas, considerando-as e relacionando-as com os sistemas de poder, pois "gênero é um campo primário no interior do qual, ou por meio do qual, o poder é articulado. $\mathrm{O}$ gênero não é o único campo, mas ele parece ter uma forma persistente e recorrente de possibilitar a significação do poder no ocidente" (SCOTT, 1995, p. 88).

As diferenças entre as práticas dos homens e das mulheres não se originam unicamente de diferenças biológicas. São também construções sociais que têm uma base material, política e ideológica, significando que a divisão social do trabalho atribuído aos homens e às mulheres historicamente são perpassadas por relações de poder em que estão inseridas, e que vão configurando o que é entendido como masculino ou feminino.

\begin{abstract}
Há uma 'narrativa convencional' sobre a maneira como as masculinidades são construídas, e que supõe, por essa narrativa, que 'toda cultura tem uma definição da conduta e dos sentimentos apropriados para os homens'. Meninos e rapazes - em sua maioria - aprenderiam tal conduta e sentimentos e, assim, se afastariam do comportamento das mulheres. Mas esta seria apenas uma das histórias possíveis. Conforme Connell, 'a narrativa convencional adota uma das formas de masculinidade em geral'. Em outras palavras, o que se tem, aqui, seria uma representação do ser homem que é mais visível (LOURO, 2011, p. 52).
\end{abstract}

Destarte, as condutas vão sendo incorporadas como habitus, consolidando-se habitus masculinos e habitus femininos, baseados numa divisão social e sexual do trabalho, permeada por relações de poder. Assim constituídos historicamente, os habitus vão implicar, de um lado, poder dos homens sobre as mulheres e, do outro, mulheres hierarquicamente submetidas aos homens. Para analisar como acontece a presença de homens em espaços caracteristicamente de mulheres e como é a docência desses na Educação Infantil, é preciso compreender melhor dois mecanismos apresentados por Bourdieu (2011), habitus e a violência simbólica. 
NUNES, P. G.; AFONSO, L. R. H.

\section{HABITUSE VIOLÊNCIA SIMBÓLICA: CONTEXTUALIZANDO CONCEITOS}

A priori, como a divisão sexual dos espaços sociais parte da constituição da organização social, "gênero é a organização social da diferença sexual" que faz com que se perceba o habitus, para justificar, no exercício da profissão docente, o fato de as mulheres serem maioria na educação das séries iniciais. Entende-se por habitus

um conjunto de valores, costumes, formas de percepções dominantes, esquemas de pensamento incorporados pelo indivíduo que lhe possibilitam perceber, interpretar o mundo social e, assim, orientar e regular suas práticas sociais. (CANEZIN, 2006, p. 114).

Habitus, aqui, é tido como uma definição para conciliar a oposição aparente entre realidade exterior e realidades individuais, sendo, para Bourdieu (2011), o habitus de certa relação social determinado pela condição de classe, e se refere tanto a uma classe quanto a um grupo. Em síntese, reflete-se sobre os significados contidos no exercício da profissão docente das séries iniciais, pois esses significados são determinados pela cultura produzida e reproduzida nas relações sociais que ali ocorrem, os quais variam, segundo Scott , de acordo com as culturas, grupos sociais e no tempo, pois não há nada no corpo, inclusos os órgãos reprodutivos femininos, que seja exclusivo na divisão social que será definida.

Concordando com Scott (1995, p. 13), como uma "ordem das coisas" refere-se às funções sociais atribuídas às mulheres, tais como a sexualidade da mulher submetida aos interesses do homem, tanto nas práticas do cuidado, da nutrição, da higiene, do controle maternal das crianças como na reprodução, fortalecendo a permanência da herança patriarcal, "para falar daquilo que é normal, natural, a ponto de ser inevitável, porque ela está presente, em estado objetivado, no mundo social e também, em estado incorporado, nos habitus, como um sistema de categorias de percepção, de pensamento e ação [...]" (BOURDIEU, 2011, p.137).

Não obstante, é nessa direção que se pode perceber como as funções sociais atribuídas aos homens e às mulheres são percebidas como invisíveis, posto que a não percepção dessa divisão social faz com que a "ordem das coisas" seja reforçada. Portanto,

Se é verdade que o princípio de perpetuação dessa relação de dominação não reside verdadeiramente, ou pelo menos principalmente, em um dos lugares mais visíveis de seu exercício, isto é, dentro da unidade doméstica, sobre a qual um certo discurso feminista concentrou todos os olhares, mas em instâncias como a Escola ou Estado, lugares de elaboração e de imposição de princípios de dominação que se exercem dentro mesmo do universo privado, é um campo de ação imensa que se encontra aberto às lutas feministas, chamadas então a assumir um papel original, e bemdefinido, no seio mesmo das lutas políticas contra todas as formas de dominação (BOURDIEU, 2011, p.10-1).

Nesse interim, procura-se situar o campo das escolas da Educação Básica. Campo esse composto por agentes sociais "portadores de um quantum de capital de diversas naturezas, seja ele capital cultural, capital social, capital político, capital artístico, capital esportivo, capital econômico, etc." (AZEVEDO, 2003, p. 24). Delimitada por valores ou 
formas de capital que lhe dão sustentação, a dinâmica social no interior de cada campo é regida pelas lutas em que os atores sociais procuram manter ou alterar as relações de força e a distribuição das formas de capital específico.

O capital cultural, que se produz nas escolas, designa divisões na atividade humana nas quais se desenrolam lutas pela conquista do poder simbólico, que produz e confirma significados nelas ali produzidos e reproduzidos. Esses conflitos consagram valores que se tornam aceitáveis nesses espaços sociais com a força simbólica, a qual é "uma forma de poder que se exerce sobre os corpos, diretamente, e como que por magia, sem qualquer coação física; mas essa magia só atua com o apoio de predisposições colocadas, como molas propulsoras, na zona mais profunda dos corpos" (BOURDIEU, 2011, p. 50).

Na perspectiva de Bourdieu (2011), o exercício desse poder se faz também através da violência simbólica que se expressa na imposição legítima com a interiorização da cultura dominante por meio de uma correlação entre as desigualdades sociais vigentes, "que é uma relação histórica, cultural e linguisticamente construída - é sempre afirmada como uma diferença de ordem natural, radical, irredutível, universal" (SOIHET, 1997, p. 11). As posições mais elevadas e prestigiadas nas instituições educacionais tendem a ser ocupadas pelos indivíduos pertencentes aos grupos socialmente dominantes, favorecendo a violência simbólica nesses espaços sociais.

O homem, associado à ideia de autoridade ligada ao poder, detém o poder na sociedade, uma sociedade patriarcal fundada neste poder do homem, do chefe de família, o qual se verifica através da "dominação masculina que está suficientemente assegurada para precisar de justificação: ela pode se contentar em ser e em dizer nas práticas e discursos que enunciam o ser como se fosse uma evidência, concorrendo assim para fazêlo ser de acordo com o dizer" (BOURDIEU, 2011, p.137).

Para Bourdieu (2011, p. 157), "os homens são também prisioneiros e insidiosamente vítimas da representação dominante, ainda que essa esteja perfeitamente de acordo com seus interesses", sendo necessário conhecer a condição de homens e mulheres na sociedade contemporânea. A dominação masculina, como bem coloca esse autor, é uma das várias formas de manifestação da violência simbólica, que é uma "violência suave, insensível, invisível para suas próprias vítimas, exerce essencialmente pelas vias puramente simbólicas da comunicação e do conhecimento, mais precisamente, do desenvolvimento, do reconhecimento ou, em última instância, do sentimento" (BOURDIEU, 2011, p. 7-8).

Além disso, fortalece atitudes e ideias que favorecem a violência física contra as mulheres, crianças e outros homens. Essa violência simbólica que Bourdieu (2011) explica não é exercida apenas sobre os dominados. Para que o domínio se perpetue e não seja percebido pelo(a) oprimido(a), é preciso que não só as identidades dos dominados, mas também as dos dominantes, sejam construídas em conformidade com o modelo de comportamento em que dominado(a) e dominante não têm a mais leve transgressão e o mais ligeiro desvio à norma.

Dessa forma, as relações sociais e de gênero na sociedade patriarcal podem ser entendidas, em sua maioria, como uma violência simbólica que garante a reprodução das estruturas de domínio, sendo que, as próprias mulheres, segundo Bourdieu, aplicam a 
NUNES, P. G.; AFONSO, L. R. H.

toda realidade e, particularmente, às relações de poder em que se percebem envolvidos esquemas de pensamento remetidos ao perfazer dessas e que se comunicam em contrariedades de ordem simbólica.

Portanto, entende-se violência simbólica como processo que promove a manutenção e reprodução das estruturas estabelecidas nas relações sociais e de gênero historicamente construídas, e que são constituidoras também das relações sociais de gênero na educação e, portanto, na docência. Nessa perspectiva, a violência simbólica é exercida por meio de um conjunto de mecanismos de conservação e reprodução das estruturas de domínio de homens sobre mulheres, reproduzidas pelas próprias mulheres e pelos próprios homens. Sendo o espaço da Educação Infantil predominantemente ocupado por mulheres, elas reproduzirão também ali as relações sociais e a violência já estabelecida.

\section{INQUIETAÇÕES}

Buscou-se, responder a vários questionamentos quanto à presença do professor homem na Educação Infantil. No entanto, apresentaremos a principal questão que norteou as demais: como se configuram as relações sociais e de gênero dos(as) trabalhadores docentes que vivenciam a Educação Infantil da Rede Municipal de Rio Verde (GO) e como se expressa isso na Educação Infantil e na comunidade escolar, quando existem professores homens atuando?

Há de se atentar que a educação básica é uma área de atuação profissional majoritariamente ocupada pelas mulheres, fato explicado historicamente pela feminização do magistério, e bem abordado por Chamon $(2005$, p. 16) quando diz:

\footnotetext{
em decorrência do capitalismo industrial em expansão e do processo de urbanização que o acompanhava, cabia a escola contribuir tanto na produção quanto na reprodução do social, visando fortalecer e legitimar as práticas culturais urbanas que interessavam às elites dominantes. Foi, também, nesse período que as mulheres passaram a ser chamadas para cumprir a nobre missão de reprodutoras dos valores sociais. Dóceis, virtuosas e abnegadas, deveriam ser elas as profissionais responsáveis pelo trabalho de preparação de mentes e comportamentos para os interesses da pátria.
}

O número de professores do sexo masculino atuando nas instituições da Educação Infantil, no Brasil, é insignificante. Conforme aponta o censo da Educação Básica, realizado em 2010 pelo Ministério da Educação MEC, 81,9\% dos (as) professores (as) da educação básica brasileira são do sexo feminino. Na Educação Infantil, este número se eleva para $96,6 \%{ }^{1}$.

Portanto, a presença de homens nessa etapa da educação básica é motivo de estranhamento por parte não só das profissionais mulheres dessas instituições, como também das famílias das crianças que as frequentam e de toda a sociedade.

Esse estranhamento acontece devido à compreensão do que seja masculinidade, entendimento que perpassa as reflexões realizadas neste estudo. Recorreu-se a estudos sobre masculinidades em Connell (1995) e Oliveira (2004), autores que discutem as masculinidades como uma construção histórica que "expressa mudanças em relação à 
aceitação social do arbitrário poder masculino e de sua hegemonia dentro do regime de gênero vigente nas culturas contemporâneas ocidentais" (OLIVEIRA, 2004, p. 142).

Oliveira (2004) apresenta que o ideal moderno de masculinidade se apoia na perspectiva de um espaço simbólico de significado estruturante, que enfoca sua construção na perspectiva do "imbricamento" entre os diversos estratos do socius, buscando assinalar os apoios institucionais variados que fundamentaram a criação de um ideal moderno de masculinidade, coletivamente partilhado, e seus destinos incertos em tempos mais recentes.

Partindo deste entendimento, de que a masculinidade se fundamenta em valores e constitui um valor social em si própria, mantendo-se e reproduzindo-se dada sua importância inegável em processos sociais diversos, a ideia da inexistência de uma forma única de construção do masculino nas sociedades aponta que "as masculinidades deveriam ser compreendidas como configurações de prática em torno da posição dos homens nas relaçôes de gênero" (CONNELL, 1995, p. 184).

Connell (1995) esclarece o uso da expressão "configuração de prática" como a ênfase nas experiências concretas presentes no cotidiano de muitos homens, e não apenas os comportamentos que as sociedades esperam dos homens nos diferentes contextos socioculturais. Na educação escolar e mesmo na própria profissão, no magistério, esse entendimento permeia as relações entre homens e mulheres.

Para entender por que o magistério é uma atividade atribuída às mulheres como uma construção histórica, viu-se como importante situar historicamente a profissão docente. Assim, recorreu-se a Pessanha (1994), autora que aponta a origem da categoria magistério a partir da divisão social e sexual do trabalho, e também a Perozim (2004), que, ao tratar da formação do masculino e do feminino, resgata o processo de configuração da profissão como sendo de mulheres.

Perozim (2004) sustenta que até meados do século XX, a mulher tinha permanência nos estudos vinculados a cursos normais, formadores de professores. Paulatinamente, houve certa identificação profissional com o sexo feminino e as mulheres adentraram estes ambientes. Porém, segundo Cláudia Vianna, conquistaram esse espaço com ambiguidade e sem remeter à profissionalização. Assim, constituiu-se a tríade mãemulher-professora, ainda mais forte na Educação Infantil com conotação voluntária ou mal-remunerada.

Para dar sequência a esta discussão, também buscou-se compreender a divisão sexual do trabalho nos estudos de Rocha (2012), Souza-Lobo (2011) e Nogueira (2004), as quais expõem que as novas características apresentadas pela política neoliberal têm acentuadas consequências na divisão sexual do trabalho, tanto no espaço produtivo como no reprodutivo e que segundo, nos anos 1990 a mundialização do capital produziu efeitos complexos, além de contraditórios, afetando desigualmente o emprego feminino e masculino.

\section{O CAMINHO PERCORRIDO}

Considerando os apontamentos teóricos descritos que perpassam a docência e as relações sociais e de gênero que indicam ferramentas básicas para a análise da 
realidade escolar, expõe-se os caminhos que foram percorridos. Desenvolveu-se a investigação por meio de estudo bibliográfico, análise documental, observação registrada em diário de campo, aplicação e análises de questionários e entrevistas nas Escolas Municipais de Educação Infantil de Rio Verde (GO).

Com a intenção de estudar o professor na Educação Infantil no Município de Rio Verde (GO), os estudos de gênero se constituíram em uma referência fundamental pela qual o objeto foi revelando-se ao longo da pesquisa e definindo algumas perguntas norteadoras para a busca de dados: quem são e como são vistos esses profissionais no município de Rio Verde? Como os professores que atuam na rede se veem nessas instituições? Como a comunidade escolar deste município, incluindo as famílias dos (as) alunos (as) e profissionais envolvidos (as) nas instituições, veem o trabalho do professor homem na educação infantil? Como se configuram as relações sociais de gênero nos espaços onde trabalham? Qual a formação dos (as) profissionais que trabalham na educação infantil?

Essas perguntas orientaram a busca por dados que oferecessem elementos para respondê-las. Primeiramente, selecionou-se a documentação que pudesse tentar verificar quem são os (as) profissionais que atuam na educação infantil e, assim, analisá-las. A documentação selecionada constituiu-se dos editais e seus resultados dos concursos, pois esses permitiriam localizar os (as) profissionais que atuam na Educação Infantil, como "os homens" aprovados para trabalhar como professores da Educação Infantil no município de Rio Verde (GO), objeto central da pesquisa sobre a qual versa este artigo.

Com os dados dos concursos sobre os (as) profissionais aprovados (as) para atuar na Educação Infantil, fez-se necessário buscar conhecer como estão organizadas as Escolas de Educação Infantil em Rio Verde (GO) e conhecer, com visitas, todas as unidades, onde esses (as) profissionais atuam.

Para essas visitas utilizou-se, a princípio, a aplicação de questionário com questões objetivas e subjetivas, para se conhecer os sujeitos que compõem o campo da pesquisa, "como o recorte que o pesquisador faz em termos de espaço, representando uma realidade empírica a ser estudada a partir das concepções teóricas que fundamentam o objeto da investigação" (MINAYO, 1998, p. 53).

Com essas visitas, pôde-se aproximar do campo e dos sujeitos que ali se encontraram e muitas informações foram sendo registradas no diário de campo, o qual proporcionou o registro das informações mais detalhadas que estavam sendo descritas quando os questionários eram aplicados.

Após todas as visitas realizadas, no total de 29 instituições da rede municipal de educação infantil de Rio Verde (GO), todos os sujeitos já haviam sido localizados. Realizouse, então, entrevistas. É sabido que pode ocorrer uma relação de dominação entre pesquisador (a) e pesquisado (a), porém existem formas de reduzir essa violência simbólica, que pode acontecer em uma situação de entrevista. Essa é explicada por Bourdieu (2011, p. 345) como "intrusão arbitrária", que está no princípio da troca, em que o conhecimento prévio dos sujeitos que serão entrevistados “(...) permite improvisar continuamente as perguntas pertinentes, verdadeiras hipóteses que se apoiam numa representação intuitiva e provisória da fórmula geradora própria ao pesquisado para provocá-lo a se revelar mais completamente" (BOURDIEU, 2011, p. 345). 
De tal modo, Bourdieu (2011) também chama a atenção sobre os sentidos que cada sujeito entrevistado pode dar às perguntas realizadas, pois as diferenças no capital cultural desse sujeito podem variar, assim como sua origem de classe.

Esse entendimento indicou a necessidade de que fossem realizadas várias entrevistas e decidiu-se por realizá-las com professoras, gestoras, coordenadoras, alguns funcionários administrativos que trabalham ou já trabalharam com o professor homem e os professores homens aprovados nos concursos para atuarem na Educação Infantil. As entrevistas foram gravadas e transcritas pela autora sempre em seguida de sua realização, para que durante a transcrição fosse possível associar as falas aos gestos e às expressões, aos silêncios, às emoções, ou seja, toda postura corporal dos(as) entrevistados(as) que poderiam ter significações foram incorporadas aos registros do diário de campo.

Após as entrevistas, em conversa com a gestora da escola que tem professor homem atuando em sala de aula, decidiu-se que para os pais e as mães de alunos (as) o instrumento mais apropriado era a aplicação de questionário com questões objetivas e subjetivas. Como sugestão também da gestora, esse questionário seria aplicado para 20 pais e/ou mães dos (as) alunos (as), sendo 10 pais e/ou mães de alunos (as) que estudam ou estudaram com o professor homem e 10 pais e/ou mães de alunos (as) que não estudaram ainda com o professor homem, mas sabem que ele trabalha na escola como professor.

No dia da aplicação compareceram apenas 15 mães e nenhum pai. Mesmo assim, consideramos que constituíam uma amostra suficiente e realizamos o trabalho. Por meio desse recurso pode-se verificar como a comunidade escolar vê o professor homem na educação infantil, tanto os pais e/ou mães dos (as) alunos (as) que tiveram o professor homem de seus (suas) filhos (as) como pais e/ou mães que ainda não tiveram essa experiência.

\section{HOMENS NOS ESPAÇOS FEMININOS: A CULTURA ESCOLAR}

Ao relacionar atividade docente com cultura escolar, especificamente na Educação Infantil, percebe-se nela uma cultura própria que é, ao mesmo tempo, reprodutora e autora de uma cultura mantida em seu interior, com valores e costumes específicos, tal como um habitus escolar.

Quando se fala aqui em habitus escolar, privilegia-se a lógica da "cultura escolar" que permite apontar, a partir de suas regras e valores, impasses pedagógicos decorrentes da relação do trabalho docente. Isso é algo percebido nas falas das mães, quando justificam o que acham de ter um professor homem na escola em que seu(sua) filho(a) estuda: "O mesmo pode passar ensinamentos e ser influência para os meninos, no comportamento deles" (Mãe $1^{2}$ ).

Cunha (1979, p. 97) escreve que o habitus, no sistema de ensino burocratizado, é entendido como a instância encarregada de exercer a ação escolar.

Nessa colocação de Cunha (1979), a compreensão da escola como mantenedora de uma cultura onde todos os habitus aparecem como "naturais" é reforçada por esses próprios habitus de "destinatários legítimos", sendo o professor homem que atua na Educação Infantil também mantenedor dos habitus que ali estão presentes, pois relata a 
gestora da escola onde o professor homem atua que, "nos planos de aula, ele tem o capricho do mesmo jeito, acolhida ele planeja da mesma forma que a professora, e também ele encontra algumas dificuldades, eu penso que assim" (Gestora Bete ${ }^{3}$ ).

Isso nos leva a refletir sobre as relações sociais e de gênero presentes nas escolas para melhor compreendemos como esse habitus perpassa essas relações, especificamente nas escolas de Educação Infantil. As crianças, através do habitus escolar, vão aprendendo a oposição e a hierarquia dos sexos ao longo do tempo em que permanecem na escola. Isso pôde ser percebido nas falas da maioria dos (as) entrevistados (as), como na fala da coordenadora quando diz que

O homem transmite mais segurança até pras crianças, porque as crianças quando veem a figura do homem, elas, assim, têm mais receio, a disciplina é melhor, mesmo as vezes o homem não tendo o total domínio da disciplina, a figura dele, eu penso, pode transmitir isso pra criança (Coordenadora Fernanda).

Louro (2003) afirma que a escola é parte importante nesse processo e também chama-nos a atenção para o modo como as instituições e suas práticas ensinam certas concepções, fazendo que certas condutas e formas de comportamento, diferenciadas pelo sexo, sejam aprendidas e interiorizadas, tornando-se quase "naturais", sendo que "tal 'naturalidade' tão fortemente construída talvez nos impeça de notar que, no interior das atuais escolas, onde convivem meninos e meninas, rapazes e moças, eles e elas se movimentam, circulam e se agrupam de formas distintas" (LOURO, 2003, p. 56).

Ampliando a colocação de Louro, sendo a escola um espaço entendido como majoritariamente de mulheres, onde geralmente não se encontram homens, reserva-se às mulheres essa herança do capital cultural. Isso pode ser notado na fala do professor Roberto, quando diz que algumas atividades podem ser desenvolvidas somente por mulheres:

[...] essa questão do homem na escola só que tem que ter muito cuidado né hoje em dia, o homem que for trabalhar na Educação Infantil ou em qualquer área não é só na Educação Infantil ele precisa ter uma postura de limites pra tá lidando com essas crianças esses alunos tem coisa que talvez uma mulher faz o homem não deve fazer pra não dá uma má impressão (Professor Roberto).

As mulheres entrevistadas reforçaram essa fala do professor Roberto e demonstraram que "interiorizaram" esse habitus e os reproduzem em suas práticas pedagógicas. Dessa forma, todas as pessoas presentes no interior da escola incorporam esse habituse os mantém. Conforme Catani (2011) o habitus, estabelecido de disposições para a ação, é a história incorporada, inscrita no corpo como um todo, nos gestos, nos modos de falar, ou seja, em tudo o que somos, e isso incorporado funciona como princípio gerador do que fazemos ou as respostas que damos à realidade e na realidade social.

Esse conceito nos direciona à busca de maior compreensão do capital cultural, que é apresentado na formação profissional dos (as) docentes que trabalham nas instituições de Educação Infantil e nos leva a esmiuçar as múltiplas dimensões da "cultura escolar", relacionada às relações sociais e de gênero que envolvem o exercício do trabalho docente nessas instituições. 
Ao serem analisadas as dimensões da cultura escolar nessas instituições, percebe-se esse habitus nas ações pedagógicas de seu interior, o que pode implicar na incorporação e reprodução de concepções excludentes do ponto de vista das relações sociais de gênero de forma sólida, visto que "entre todas as ações pedagógicas que sofremos, as mais decisivas são as mais precoces, as que sofremos durante a infância, e que tiveram como resultado inculcar-nos um habitus primário" (BONNEWITZ, 2003, p.156).

Partindo dessa colocação de Bonnewitz (2003), pode-se dizer que, no interior das instituições, o habitus da cultura das funções sociais destinadas às mulheres - tais como da reprodução, ou seja, as práticas do cuidado, do controle maternal das crianças -, são "inculcadas" como função das mulheres e não dos homens, que não detêm esses saberes considerados historicamente como "naturais" das mulheres. Accardo (1991, p. 105 apud ASSUNÇÃO, 1996, p. 16) complementa dizendo que, não entendendo de forma consciente a força do habitus na atitudes e reações, as pessoas rotulam as consequências desse na 'conta de causas misteriosas'.

Com base nesse habitus, marcam-se, definem-se e enquadram-se os sujeitos presentes nas escolas. Contudo, quem não corresponde a essa demarcação se constituirá pela diferença. Assim, são construídas identidades, ordenando e constituindo os sujeitos. Cabe-nos, então, num processo de ruptura, buscar compreender esses indivíduos que se constituem na diferença.

\section{CONSIDERAÇÕES}

A investigação permitiu-nos uma aproximação com os professores e as professoras da educação infantil do município de Rio Verde. Da perspectiva das relações sociais e de gênero foi possível analisar que essa divisão se expressa na construção social do masculino e do feminino. Percebe-se que homens e mulheres ocupam os mesmos espaços sociais, embora seja comum que os homens desempenhem funções sociais tidas como masculinas e as mulheres desempenhem funções sociais consideradas como femininas, e que tais funções não são naturais, portanto podem ser modificadas.

As discussões sobre a diferenciação do trabalho docente de homens e de mulheres incluem ou excluem materialmente professores e professoras em suas carreiras pelas instituições. Observou-se haver maiores oportunidades aos homens para abandonarem a sala de aula, a fim de ocupar cargos de administração, chefia ou aqueles mais próximos a um padrão social de masculinidade, no caso, secretaria, coordenação e professor de apoio. Esta constatação remete ao processo histórico de construção da divisão social e sexual do trabalho.

O professor homem na atividade docente parece favorecer mais a manutenção e legitimação da divisão sexual do trabalho do que sua subversão, pois ao mesmo tempo em que são preparados profissionais para atividades "masculinas" e "femininas", são também reproduzidas ações e discursos que naturalizam essa divisão.

De modo geral, os professores pesquisados parecem temer a experiência do "cuidar" de crianças na educação infantil. Neste sentido, o gênero masculino parece ser 
NUNES, P. G.; AFONSO, L. R. H.

um gênero retirante que passa facilmente para outros espaços da instituição em função do temor do julgamento da possibilidade do abuso sexual.

A instituição escolar é um lugar social onde surgem relações de poder que perpassam todas as pessoas. O poder disciplinar, presente na sociedade patriarcal, apresenta-se na instituição escolar de diversas formas. Todos os indivíduos entrevistados apresentaram em suas falas essa característica, afirmando que o homem concede mais autoridade e segurança como professor na instituição. Desta forma, entende-se que as relações de poder perpassam a atividade docente do professor homem.

Neste artigo, apresentamos resultados obtidos em pesquisa que objetivou investigar e analisar o professor homem na Educação Infantil da Rede Municipal de Ensino de Rio Verde (GO) e como este é percebido pela comunidade escolar. O estudo desenvolveu-se mediante questionamentos sobre a docência do professor homem na Educação Infantil e ao habitus do reconhecimento de mulheres nessa etapa. A atuação docente dos professores homens do município de Rio Verde nessa etapa é marcada por relações de poder que permeiam as relações sociais e de gênero presentes nos espaços sociais, e que homens em espaços considerados historicamente como femininos apresentam características da prática docente associadas à masculinidade tradicional, como um habitus cultural mantido pela violência simbólica.

Artigo recebido em: $25 / 08 / 2017$

Aprovado para publicação em: 11/12/2017

\section{TEACHING AND GENDER: MALE TEACHER IN EARLY CHILDHOOD EDUCATION}

ABSTRACT: This paper presents some data resulted from a research whose aim was to investigate and analyze the male teacher in early childhood education of the municipal public school system in Rio Verde, Goiás, Brazil, and how he is perceived by local community. The study was developed by some questionings about teaching of male teacher in early childhood education and also the habitus of recognition by women in this educational stage. The teaching performance of male teacher in Rio Verde is marked by power relations that permeate the social and gender relations present in social spaces, and the men in spaces considered historically as feminine, present the characteristics of teaching practice associated with traditional masculinity, such as cultural habitus maintained by symbolic violence.

KEYWORDS: Teaching. Social Relations and Gender. Early Childhood Education. Habitus.

\section{DOCENCIA Y GÉNERO: EL PROFESOR EN LA EDUCACIÓN INFANTIL}

RESUMEN: En este artículo, presentamos algunos de los resultados obtenidos en la investigación de maestría que tuvo el objetivo de investigar y analizar al profesor en la Educación Infantil de la Red Municipal de Enseñanza de Río Verde (GO) y cómo éste es percibido por la comunidad escolar. El estudio se desarrolló mediante cuestionamientos sobre la docencia del profesor en la Educación Infantil y el habitus del reconocimiento de mujeres en esa etapa de la educación. La actuación de estos profesores de Río Verde está marcada por relaciones de poder que permean las relaciones sociales y de género presentes en los espacios sociales. Además, los hombres en espacios considerados históricamente femeninos, presentan el mantenimiento de características de la 
Docência e gênero: o professor homem...

práctica docente asociadas a la vida masculinidad tradicional, como un habitus cultural mantenido por la violencia simbólica.

PALABRAS CLAVE: Docencia. Relaciones de Poder y Género. Educación infantil. Habitus.

\section{NOTAS}

1) Dados disponíveis no site: www.portal.mec.gov.br/. Link Educacenso.

2) Os questionários aplicados às mães foram enumerados de forma aleatória.

3) Todos os nomes utilizados para se referir aos sujeitos da pesquisa são fictícios.

\section{REFERÊNCIAS}

ASSUNÇÃO, M. M. S. Magistério primário e cotidiano escolar. Campinas: Autores Associados, 1996. (Coleção Polêmicas do nosso tempo, v.53)

AZEVEDO, M. L. N. Espaço social, campo social, habitus e conceito de classe Social em Pierre Bourdieu. Revista Espaço Acadêmico, ano III, n²4, maio, 2003.

BONNEWITZ, P. Primeiras lições sobre a sociologia de P. Bourdieu / Patrice Bonnewitz. Tradução de Lucy Magalhães. Petrópolis: Vozes, 2003.

BOURDIEU, P. A dominação masculina. Tradução de Maria Helena Kühner. 10 ed. Rio de Janeiro: Bertrand Brasil, 2011.

BRUSCHINI, M. C. A. Trabalho e Gênero no Brasil nos Últimos Dez Anos. Cadernos de Pesquisa, v. 37, n. 132, p. 537-572, set./dez. 2007.

CANEZIN, M. T. Introdução à teoria e ao método em ciências sociais e educação. Goiânia: Editora UCG, 2006.

CARVALHO, M. P. Gênero e trabalho docente: em busca de um referencial teórico. In: BRUSCHINI, C.; HOLLANDA, H. B. (Orgs.). Horizontes Plurais - novos estudos de Gênero no Brasil. São Paulo: FCC; Ed. 34, 1998.

. No coração da sala de aula: gênero e trabalho docente nas séries iniciais. São Paulo: Xamã, 1999.

CATANI, D. B. A educação como ela é. Revista Educação, São Paulo, nº 05, 2011. 
NUNES, P. G.; AFONSO, L. R. H.

CHAMON, M. Trajetória de feminização do magistério: ambiguidades e conflitos. Belo Horizonte: Autêntica, 2005.

CONNEL, R. Políticas da masculinidade. Educação e Realidade, Porto Alegre, v. 20, n.2, p. 185-206, jul./dez. 1995.

CUNHA, L. A. Notas para uma leitura da teoria da violência simbólica. Revista Educação \& Sociedade, set. 1979.

LOURO, G. L. Mulheres na sala de aula. In: DEL PRIORI, M. (Org.). História das Mulheres no Brasil. São Paulo: Contexto, 2011. p. 443-481.

LOURO, G. Gênero, sexualidade e educação: Uma perspectiva pós-estruturalista. Petrópolis: Vozes, 2003.

NOGUEIRA, C. M. A feminização no mundo do trabalho: entre a emancipação e a precarização. Campinas, SP: Autores Associados, 2004.

OLIVEIRA, P. P. Vivências masculinas: interacionais e identitárias: a construção social da masculinidade. Belo Horizonte: Ed. da UFMG; Rio de Janeiro: Ed. do IUPERJ, 2004.

. A construção social da masculinidade. Belo Horizonte: Ed. da UFMG; Rio de Janeiro: Ed. do IUPERJ, 2004.

PEDRO, J. M. Traduzindo o debate: o uso da categoria gênero na pesquisa histórica. História, São Paulo, v.24, n.1, p.77-98, 2005.

PEROZIM, L. Masculino e feminino no plural: ao reproduzir preconceitos de gênero, escola prejudica formação e desempenho de meninos e meninas. Revista Educação, n.109, 2004.

PESSANHA, E. Ascensão e queda do professor. São Paulo: Cortez, 1994.

ROCHA, A. Trabalhadoras da Faet. condições de trabalho e sobrecarga doméstica. São Paulo: Anita Garibaldi; Fundação Maurício Grabois, 2012.

SCOTT, J. Gênero: uma categoria útil de análise. Gênero e Educação: Educação e Realidade, Porto Alegre, v. 20, n. 2, p. 71-100, jul./dez. 1995.

SOIHET, R. Violência simbólica: saberes masculinos e representações femininas. Revista Estudos Feministas, v. 5, n. 1, 1997.

PatríCIA GouvÊA Nunes: Mestra em Educação pela Pontifícia Universidade Católica de Goiás - PUC-GO (2013), na linha de pesquisa Estado, Políticas e Instituições 
Educacionais. Possui especialização em Gênero e Diversidade na Escola pela UFG - Campus Catalão-Go (2012) e em Ensino de Filosofia e Sociologia pela Faculdade Católica de Anápolis-Go (2007). Graduada em Pedagosia pela UniRV - Universidade de Rio Verde (2004). Atua como professora do Instituto Federal Goiano, Campus Rio Verde, Goiás, atuando principalmente nos seguintes temas: políticas educacionais, formação de professores (as), estágio supervisionado, relações sociais de sênero, relações étnico-raciais, diversidade, filosofia, metodologia científica, avaliação e didática.

E-mail: patricia.nunes@ifgoiano.edu.br

LúCIA RINCON Helena Afonso: Possui graduação em História pela Universidade Federal de Goiás (1974), mestrado em História Regional pela Universidade Federal de Goiás (1981), e doutorado em Educação pela Universidade Estadual Paulista Júlio de Mesquita Filho (2002). Professora adjunto da Pontifícia Universidade Católica de Goiás. Integrante do PPGE/PUC Goiás, na linha de Pesquisa Estado, Políticas e Instituições Educacionais. Pesquisadora do Grupo de Pesquisa registrado no CNPQ, Políticas Educacionais e Gestão Escolar e da Rede de Pesquisa registrada na FAPEG, Estado, Instituições e Políticas Educacionais. Desenvolve o projeto OBSERVATÓRIO SÉCULO XXI? Professor@s formad@s na PUC Goiás em tempos de produção flexível e sociedade midiática: Configurações de Gênero e Representações Profissionais. Foi membro da Comissão da Verdade da Confederação Nacional de Trabalhadores em Estabelecimentos de Ensino/CONTEE, é Membro efetivo do Conselho Nacional dos Direitos da Mulher, representando a União Brasileira de Mulheres. Atualmente é Diretora de Comunicação da Associação dos Professores da Universidade católica de Goiás, membro da Coordenação Nacional da União Brasileira de Mulheres.

E-mail: luciarincon@gmail.com 